\title{
Pedicle TRAM Flap Procedure
}

National Cancer Institute

\section{Source}

National Cancer Institute. Pedicle TRAM Flap Procedure. NCI Thesaurus. Code C107383.

A type of breast reconstruction in which a section of skin, muscle, fat, and blood vessels from the abdomen is separated from surrounding tissue while retaining its blood supply, and tunneled under the skin to form a new breast mound. 